\section{Relative Resistance of Ornamental Flowering Bulbs to Feeding Damage by Voles}

\author{
Paul D. Curtis ${ }^{1,3}$, Gwen B. Curtis ${ }^{2}$, and William B. Miller ${ }^{2}$
}

ADDITIONAL INDEX WORDs. plant secondary metabolites, crocus, camass, daffodil, dwarf iris, fritillaria, glory of the snow, grape hyacinth, onion, painted arum, snowdrop, squill, tulip

\begin{abstract}
Summary. Many plants have mechanisms of physical or chemical resistance that protect them from herbivores in their environment. Vertebrates such as meadow voles (Microtus pennsylvanicus) cause significant damage to ornamental plantings and home gardens. Our goal was to identify flowering bulbs that could be used to design more herbivore-resistant home landscapes. Single-choice feeding trials with captive prairie voles (Microtus ochrogaster) were used to assess the relative resistance of 30 bulb varieties to deter rodents from consuming fresh plant material and freeze-dried, powdered bulb mixed with a preferred food (applesauce). Each fresh bulb and dried-bulb/applesauce mix was offered twice to 12 to 15 pairs of adult prairie voles. Bulb varieties that resulted in the lowest mean consumption were assumed to be the most resistant to feeding activity. With fresh bulbs, only tulips (Tulipa spp.) exhibited no resistance to prairie vole feeding. Dried-bulb/applesauce mixes containing hyacinth (Hyacinth spp.), crocus (Crocus spp.), corn leaf iris (Iris bucharica), dutch and dwarf iris (Iris reticulata), onion (Allium spp.), and squill (Scilla siberica) were also readily consumed, and thus, these bulbs could be damaged at sites with high rodent activity. Daffodil (Narcissus spp.), painted arum (Arum italicum), camass (Camassia leichtlinii), glory-of-the-snow (Chinodoxa forbesii), autumn crocus (Colchicum spp.), crown imperial (Fritillaria imperialis), persian fritillaria (Fritillaria persica), snowdrop (Galanthus nivalis), and grape hyacinth (Muscari armeniacum) bulbs were resistant to prairie vole feeding in both forms (fresh bulbs and dried-bulb/applesauce mixes). Consequently, all of the specialty flower bulbs tested, except tulip, exhibited some resistance to prairie vole feeding in their fresh form, and could be suitable for designing herbivore-resistant landscapes.
\end{abstract}

$\mathrm{F}$ lower bulbs provide an important design and color component in the landscape, and are very popular with the gardening public. They are especially valued for their diversity of flower shapes, vibrant colors, sizes, and flowering periods. They are effective in large, massed plantings, or in smaller-scale garden situations.

Herbivorous mammals cause significant damage to ornamental plants

\footnotetext{
This project was funded by the U.S. Department of Agriculture-Agricultural Research Service, the Floral and Nursery Crops Initiative, the Cornell Agricultural Experiment Station, Hatch Project 147-412, and by Anthos (Hillegom, The Netherlands).

We thank F. Vermeylen (Office of Statistical Consulting, Cornell University) for advice on the statistical analyses. M. Richmond (New York Cooperative Fish and Wildlife Research Unit, USGS-BRD, Cornell University) provided advice on the breeding biology and maintenance of voles, and gave valuable comments on the manuscript. D. Brown (Department of Animal Science, Cornell University) provided helpful comments on plant secondary compounds.

${ }^{1}$ Department of Natural Resources, Cornell University, Ithaca, NY 14853.

${ }^{2}$ Department of Horticulture, 134 Plant Science Building, Cornell University, Ithaca, NY 14853.

${ }^{3}$ Corresponding author. E-mail: pdcl@cornell.edu.
}

in home landscapes (Conover et al., 1995 ) and nurseries (Bromley et al., 1992; Lemieux et al., 2000). Fencing, netting, and repellents may reduce aboveground damage to plants in many situations. However, these techniques for protecting ornamentals are expensive and often aesthetically unappealing. Also, methods used to prevent damage to aboveground plants may be ineffective for burrowing mammals such as pine voles (Pitymys pinetorum) or eastern chipmunks (Tamias striatus). More costeffective and long-term strategies are demanded by homeowners to protect flowering bulbs. Although no specific statistics are reliable, anecdotal evidence from members of the North American flower bulb distribution industry suggests that predation by white-tailed deer (Odocoileus virginianus) is a serious issue, and has led, in some cases, to as much as an $80 \%$ to $90 \%$ reduction in the volume of tulip bulbs sold for landscape purposes. Through careful plant selection, it may be possible to design herbivoreresistant landscapes (Fargione et al., 1991).

Many secondary plant compounds are known to be unpalatable or toxic to herbivores (Bryant et al., 1992; Harborne, 1991; Meyer and Karasov, 1991; Tahvanainen et al., 1991). Only a few have been tested for their effects on voles (Curtis et al., 2002, 2003; Jung and Batzli, 1981; Lindroth and Batzli, 1984; Lindroth et al., 1986). Daffodils contain many steroidal alkaloids that inhibit animal feeding (Kreh and Matusch, 1995; Ries et al., 2001). However, tulips are readily consumed by white-tailed deer, meadow voles, and other herbivores. Controlled research trials to evaluate the relative herbivore resistance of flowering bulb varieties have not previously been conducted. Our research objective was to identify flowering bulbs that could be used to design more vole-resistant home landscapes.

\section{Materials and methods}

VOLE SELECTION AND MAINTENANCE. We used compatible adult (weighing $>40 \mathrm{~g}$ ) same-sex pairs of laboratory-reared prairie voles from an out-bred colony that has been maintained at Cornell University since 1969. The origin and maintenance of this colony is described elsewhere (Richmond and Conaway, 1969). This species was used rather than native pine or meadow voles because of the ease of handling these long-term captive animals. Voles are social mammals (Getz et al., 1993) and exhibit normal feeding behavior in pairs or family groups. Twelve to 15 vole pairs were used in each feeding trial. Each pair was housed in a clear polycarbonate cage $(10 \times 19 \times 8$

\begin{tabular}{llll}
\hline $\begin{array}{l}\text { Units } \\
\begin{array}{l}\text { To convert U.S. to SI, } \\
\text { multiply by }\end{array}\end{array}$ & U.S. unit & SI unit & $\begin{array}{l}\text { To convert SI to U.S., } \\
\text { multiply by }\end{array}$ \\
\hline 2.54 & inch(es) & $\mathrm{cm}^{3}$ & 0.3937 \\
16.3871 & inch $^{3}$ & $\mathrm{~cm}^{3}$ & 0.0610 \\
28.3495 & $\mathrm{oz}$ & $\mathrm{g}$ & 0.0353 \\
$\left({ }^{\circ} \mathrm{F}-32\right) \div 1.8$ & ${ }^{\circ} \mathrm{F}$ & ${ }^{\circ} \mathrm{C}$ & $\left(1.8 \times{ }^{\circ} \mathrm{C}\right)+32$
\end{tabular}


inches) in a controlled environment room with a 14-h/10-h light/dark cycle at 21 to $24^{\circ} \mathrm{C}$, and $30 \%$ to $70 \%$ relative humidity. Free access to water and commercial food pellets (Tekla Rabbit Diet 8630 and Tekla Woodchuck Diet 7778; Harlan, Madison, IL) were provided during feeding trials. The cages were supplied with softwood shavings, and were cleaned biweekly.

EXPT. 1. Vole BIOASSAYS WITH FRESH BULBS. We used 30 varieties and species of flower bulbs, selecting a range that is often planted in home landscapes (Fig. 1). In Sept. 2001, bulbs were shipped from The Netherlands to Ithaca, NY. Bulbs were held ventilated at $17{ }^{\circ} \mathrm{C}$ from September through Jan. 2002. For fresh-bulb trials, samples of each variety were removed from storage 1 to $2 \mathrm{~h}$ before the feeding assays with captive voles. Feeding trials were usually conducted between 0900 and 1100 HR each morning. The voles became accustomed to this feeding schedule, and would vocalize and get excited when we entered the laboratory to prepare the bulbs or bulb mixes.

We conducted single-choice feeding trials with the entire prairie vole colony on 2 consecutive days for each bulb variety (Fig. 2). Depending on the weight of an individual bulb, a whole bulb, part of a bulb, or several small bulbs (range of 3-16 g, except for autumn crocus) was offered for 15 min to each of 12 to 15 prairie vole pairs. All bulb samples consisted of the bulb "heart" (central region) and any layers of scales. Based on results from our preliminary studies, prairie vole pairs consumed an average of about $3 \mathrm{~g}$ fresh weight of 'Apeldoorn' tulip (a preferred variety) in $15 \mathrm{~min}$. This level of consumption was similar to that for apple (Malus $\times$ domestica) slices and applesauce. Therefore, 'Apeldoorn' tulip served as a control, and was offered for one day between each of the 2-d trials. Twelve to 15 prairie vole pairs were simultaneously offered $3 \mathrm{~g}$ of the selected bulb variety for $15 \mathrm{~min}$, and the remaining bulb parts were weighed. For all 30 experimental varieties, the feeding trials were conducted on 2 consecutive days for each prairie vole pair. Consequently, for any single bulb variety and species, we measured consumption for 24 to 30 vole pairs (12-15 pairs $\times 2 \mathrm{~d}$ ). Bulb varieties were

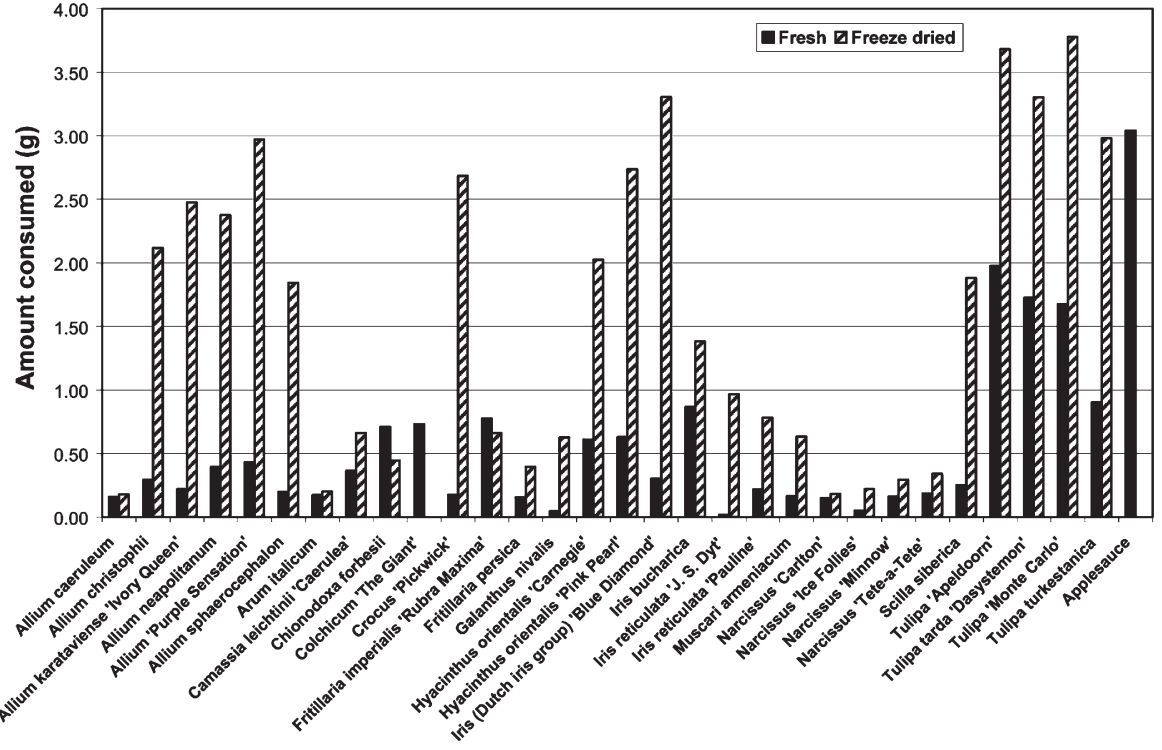

Bulb offered

Fig. 1. Average weight consumed of fresh bulb tissue ( $3 \mathrm{~g}$ offered $)$ or freeze-dried bulb/applesauce mixes ( $4 \mathrm{~g}$ offered) during 15 - min feeding trials by captive prairie vole pairs for individual bulb varieties and species. We conducted single-choice feeding trials for each bulb variety with 12 to 15 pairs of prairie voles on $2 \mathrm{~d}$ (consecutive). Freeze-dried bulb powder was mixed with applesauce to reconstitute the powder at a $25 \%$ concentration of bulb (by weight) immediately before each feeding trial $(\mathrm{l} g=0.0353 \mathrm{oz})$.

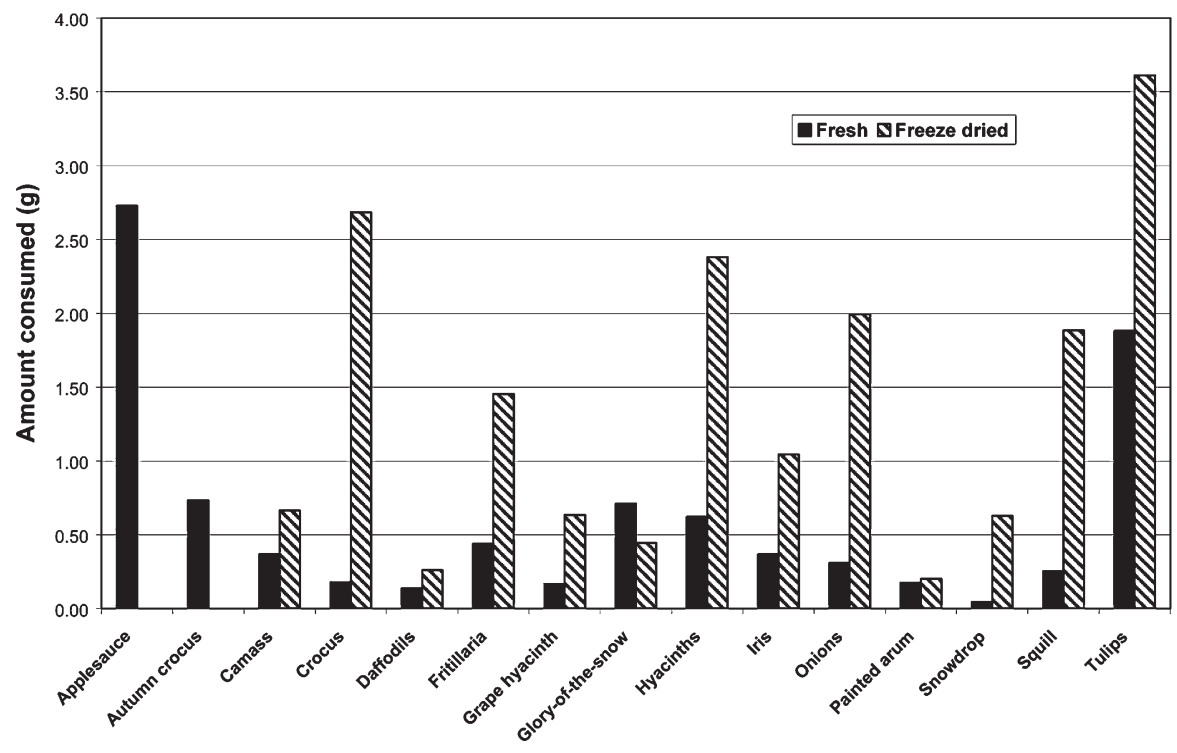

Bulb offered

Fig. 2. Average weight consumed of fresh bulb tissue ( $3 \mathrm{~g}$ offered) or freeze-dried bulb/applesauce mixes ( $4 \mathrm{~g}$ offered) during 15 -min feeding trials by captive prairie vole pairs, sorted by variety for relative comparison. We conducted single-choice feeding trials for each bulb variety with 12 to 15 pairs of prairie voles on $2 \mathrm{~d}$ (consecutive). Freeze-dried bulb powder was mixed with applesauce to reconstitute the powder at a $25 \%$ concentration of bulb (by weight) immediately before each feeding trial $(1 \mathrm{~g}=\mathbf{0 . 0 3 5 3} \mathrm{oz})$.

selected in random order until all 30 were tested.

EXPT. 2. VOLE BIOASSAYS WITH FREEZE-DRIED BULBS. To compare the relative palatability of bulb varieties with equivalent concentration by weight, we mixed finely ground, freezedried bulb material with unsweetened 
applesauce. Applesauce was mixed with the dried bulb powder because apples are highly preferred by voles (Byers, 1984, Curtis et al., 2002). In previous research trials (Curtis et al., 2002,2003 ), applesauce served as a medium for offering test materials during palatability studies. As in previous investigations, we assumed that the lowest mean consumption of dried-bulb/applesauce mixes represented the least palatable combination, hence, the least palatable bulb varieties and species. Before this study, we compared prairie vole consumption of apple slices, 'Apeldoorn' tulip bulb quarters, and applesauce to confirm that mean consumption was 3 to $4 \mathrm{~g}$ when offered to a prairie vole pair for $15 \mathrm{~min}$.

Fresh bulbs were prepared for freeze-drying by removing the tunic (if necessary) and by cutting large- or medium-sized bulbs into $\approx 1-\mathrm{cm}^{3}$ pieces. Bulb pieces were frozen in liquid nitrogen and then freeze-dried. Tissues were then ground to a powder with a Wiley mill with a 20 -mesh screen and stored desiccated at $17^{\circ} \mathrm{C}$. The bulb powder was mixed with applesauce to reconstitute the powder at a $25 \%$ concentration of bulb (by weight) immediately before each feeding trial. The powdered bulb tissue provided a constant dry weight of bulb for relative comparison between varieties. The powder was reconstituted with applesauce to offer a consistent wet weight $(4 \mathrm{~g})$ of bulb-applesauce mix for each prairie vole feeding trial. Applesauce was used to reconstitute the bulb powder rather than water because applesauce was a preferred food for prairie voles, and only the most resistant bulb varieties would deter prairie voles from feeding on the bulb-applesauce mix offered.

We conducted two single-choice feeding trials with each bulb variety. Twelve to 15 prairie vole pairs were each offered $4 \mathrm{~g}$ of the selected bulbapplesauce mix concurrently for 15 min, and the consumption was recorded. No more than one trial per day was conducted between Jan. and May 2002. Each bulb/applesauce mix was offered to all prairie vole pairs on $2 \mathrm{~d}$ (consecutive), and the order in which the mixes were offered was randomized. To maintain feeding interest in the dried-bulb/ applesauce mixes, the control mix with 'Apeldoorn' tulip/applesauce was offered between each set of variety trials.

Data analyses. Mean consumption for each bulb variety was calculated and plotted using Minitab (release 13.1; Minitab, State College, PA). We conducted multiple comparisons of the grams of fresh bulb or dried-bulb/applesauce mix consumed by the vole pairs for each variety using PROC MIXED of SAS (version 7.0; SAS Institute, Cary, NC). We controlled for vole-pair effects by including cage number as a random factor in the analysis. Consumption (grams) of bulbs or dried-bulb/applesauce mix was the dependent variable. Form (fresh or freeze-dried) and variety were classified as independent factors in the analyses.

\section{Results and discussion}

There were significant differences in the relative palatability of bulbs tested for both variety $(\mathrm{F}=294.46$, $P<0.001)$ and form $(\mathrm{F}=262.45$, $P<0.001$; Fig. 1). Applesauce-tulip mixes exhibited the highest consumption (Fig. 1). Apples and tulips are highly preferred foods for voles and were readily consumed. In the fresh form, prairie voles found the other flowering bulbs tested to be relatively unpalatable, usually consuming less than $0.5 \mathrm{~g}$ of the $4 \mathrm{~g}$ offered on average. Considering fresh and freeze-dried bulb forms offered, the least palatable bulbs were daffodil, grape hyacinth, painted arum, and snowdrop.

For most varieties, voles consumed significantly more bulb material when the freeze-dried, powdered tissue was mixed with applesauce at a $25 \%$ concentration (Fig. 1). Although the amount of daffodil consumed appeared similar for both forms (Fig. $1)$, voles did eat significantly more bulb-applesauce mix $(\mathrm{F}=8.66, P=$ $0.003)$. Consumption of fresh bulb and powdered bulb-applesauce mixes was not significantly different for painted arum $(\mathrm{F}=1.47, P=0.22)$, glory-of-the-snow $(\mathrm{F}=0.06, P=$ $0.80)$, and persian fritillaria $(\mathrm{F}=$ 3.37, $P=0.06$ ). We did not compare fresh and powdered forms of autumn crocus because seven voles died when they consumed fresh bulbs. This reduced the number of vole pairs from 15 to 12 . New voles were added to the study to maintain at least a dozen pairs for bioassays.
Within varieties, consumption of bulb material by voles was similar (Fig. 1). The four tulip varieties were consistently eaten in fresh and driedbulb/applesauce mixes. Conversely, the four daffodil varieties were considered unpalatable for voles in both forms. Only corn leaf iris was eaten as a fresh bulb. 'Blue Diamond' dutch iris was more palatable than the other three varieties when dried-bulb powder was mixed with applesauce. Five of six onion varieties were relatively unpalatable as fresh bulbs, but were readily eaten when bulb powder was mixed with applesauce. Blue globe onion (Allium caeruleum) was the only variety that was unpalatable when freeze-dried bulb was mixed with applesauce.

Many studies have shown that plants that are unpalatable to herbivores tend to contain secondary plant compounds (Bryant et al., 1991; Harborne, 2000; Reichardt et al., 1990). The few relevant studies specific to voles supports this finding (Lindroth et al., 1986; Marquis and Batzli, 1989; Roy and Bergeron, 1990). Many of these secondary compounds have strong purgative effects, and some are poisonous to livestock (Harborne et al., 1999; Muenscher, 1951). Daffodils contain many toxic alkaloids (Harborne et al., 1999; Kreh and Matusch, 1995; Tojo, 1991), and are poisonous to humans and other animals (Kingsbury, 1994). Therefore, we suggest that the observed consumption of fresh bulbs, or dried-bulb/applesauce mixes, was largely due to effects of secondary plant compounds.

Curtis et al. (2002) demonstrated that concentration of secondary plant compounds may be responsible for the variation in palatability of plant material. Vole consumption of daffodil bulb/applesauce mixes was significantly greater at $14 \%$ bulb concentration in the mix than a $25 \%$ or $50 \%$ concentration (data not shown). For this study, we standardized all driedbulb/applesauce mixes at $25 \%$ for relative comparisons of vole consumption across varieties. Consistent with previous studies (Curtis et al., 2002), bulb-applesauce mixes containing daffodil were unpalatable, while those with onion were readily consumed.

The concentration of secondary compounds in autumn crocus was possibly toxic for seven voles. 
Colchicine is a known mutagen and may arrest cell meiosis (Harborne et al., 1999). Pathology analysis conducted by the Animal Health Diagnostic Center at the New York College of Veterinary Medicine (Ithaca, NY) could not conclusively determine that the voles died from colchicine poisoning. However, acute hepatic necrosis and mucosal necrosis in the stomach was documented in the necropsy report. Five of the seven prairie voles died within $24 \mathrm{~h}$ after consuming from 0.2 to $1.8 \mathrm{~g}$ of fresh autumn crocus bulb. However, other prairie voles consuming similar amounts of fresh bulb survived with no apparent ill effects. Further research is needed to understand the potential toxic effects of autumn crocus.

With fresh bulbs, only tulip exhibited little resistance to prairie vole feeding. Dried-bulb/applesauce mixes containing hyacinth, crocus, dwarf iris, onion, and squill were also readily consumed by prairie voles (Fig. 1), and thus, these bulbs could be damaged at field sites with high rodent activity. Daffodils, painted arum, camass, glory-of-the-snow, autumn crocus, fritillaria, snowdrop, and grape hyacinth bulbs (Fig. 2) were resistant to prairie vole feeding in both forms (fresh bulbs and dried-bulb/applesauce mixes). Consequently, all of the flower bulbs tested, except tulip, exhibited some resistance to prairie vole feeding in their fresh form, and could be suitable for designing herbivore-resistant landscapes.

For certain varieties and species (hyacinths, crocus, dwarf iris, onion, squill, grape hyacinth, snowdrop, and camass), prairie voles consumed significantly more dried-bulb/applesauce mix than fresh bulb (Fig. 1). The presence of aromatic compounds, or structural components such as lignin and silica, could explain these differences in consumption. The grinding and freeze-drying process may have altered or destroyed certain phytochemicals. Altering fresh bulbs by drying, grinding, or chemical extraction changes their repellency to mammalian herbivores (Ries et al., 2001). There is opportunity for future research to determine the actual means of herbivore resistance for these bulbs. Likely, multiple compounds are involved with herbivore resistance (Curtis et al., 2003).
There are underlying genetic pathways for producing plant secondary compounds and other defensive mechanisms. Swain (1978) argued that the nature of plant chemical constituents provided the most important force in plant-animal coevolution during the past 400 million years. Flowering bulbs contain alkaloids and many other compounds that repel herbivores. The biochemical synthesis of these compounds is complex, and would be difficult to transfer between varieties.

\section{Conclusion}

Our study is unique in that we assessed the relative palatability of fresh bulbs and dried-bulb/applesauce mixes for prairie voles. At sites where rodent damage to flowering plants has occurred repeatedly over many years, bulbs including daffodils, painted arum, camass, gloryof-the-snow, autumn crocus, persian fritillaria, snowdrop, and grape hyacinth exhibit resistance and should be planted. In areas where herbivore damage is infrequent, bulbs including hyacinth, crocus, iris, onion, tulip, and squill also could be selected. Whenever rodents are present, tulip bulbs should be protected with repellents or physical barriers. These costly protective measures can be avoided by planting the most resistant bulb varieties at sites where frequent pine vole or meadow vole damage is anticipated. Also, removal of mulch from planting beds may reduce meadow vole tunneling and associated plant damage (Merwin et al., 1999).

\section{Literature cited}

Bromley, P.T., M.L. Parker, and W.T. Sullivan, Jr. 1992. Controlling vole damage in commercial orchards and ornamental nurseries. North Carolina Agr. Ext. Serv. Publ. 472.

Bryant, J.P., F.D. Provenza, J. Pastor, P.B. Reichardt, T.P. Clausen, and J.T. du Toit. 1991. Interactions between woody plants and browsing mammals mediated by secondary metabolites. Annu. Rev. Ecol. Syst. 22:431-446.

Bryant, J.P., P.B. Reichardt, and T.P. Clausen. 1992. Chemically mediated interactions between woody plants and browsing mammals. J. Range Manage. 45:18-24.

Byers, R.E. 1984. Control and management of vertebrate pests in deciduous orchards of the eastern United States. Hort. Rev. (Amer. Soc. Hort. Sci.) 6: 253-285.

Conover, M.R., W.C. Pitt, K.K. Kessler, T.J. Dubow, and W.A. Sanborn. 1995. Review of human injuries, illnesses, and economic losses caused by wildlife in the United States. Wildl. Soc. Bul. 23:407414.

Curtis, P.D., E.D. Rowland, and G.L. Good. 2002. Developing a plant-based vole repellent: Screening of ten candidate plants. Crop Prot. 21:299-306.

Curtis, P.D., E.D. Rowland, M.M. Harribal, G.B. Curtis, J.A. Renwick, M.D. Martin-Rehermann, and G.L. Good. 2003. Plant compounds in Pachysandra terminalis that act as feeding deterrents to prairie voles (Microtus ochragaster). HortScience 38:390-394.

Fargione, M.J., P.D. Curtis, and M.E. Richmond. 1991. Resistance of woody ornamental plants to deer damage. Cornell Coop. Ext. Home-Grounds-Garden Fact Sheet 800.00.

Getz, L.L., B. McGuire, T. Pizzuto, J.E. Hofmann, and B. Frase. 1993. Social organization of the prairie vole (Microtus ochrogaster). J. Mammal. 74:44-58.

Harborne, J.B. 1991. The chemical basis of plant defense, p. 45-60. In: R.T. Palo and C.T. Robbins (eds.). Plant defenses against herbivory. CRC Press, Boca Raton, FL.

Harborne, J.B. 2000. Arsenal for survival: Secondary plant products. Taxon 49: 435-449.

Harborne, J.B., H. Baxter, and J.P. Moss. 1999. Phytochemical dictionary: A handbook of bioactive compounds from plants. 2nd ed. Taylor Francis, London.

Jung, H.J.G. and G.O. Batzli. 1981. Nutritional ecology of microtine rodents: Effects of plant extracts on the growth of arctic microtines. J. Mammal. 62:286292.

Kingsbury, J.M. 1994. Common poisonous plants. Cornell Coop. Ext., Info. Bul. 104.

Kreh, M. and R. Matusch. 1995. Omethyloduline and $\mathrm{N}$-demethylmasonine, alkaloids from Narcissus psendonarcissus. Phytochemistry 38:1533-1535.

Lemieux, N., B.K. Maynard, and W.A. Johnson. 2000. A regional survey of deer damage throughout Northeast nurseries and orchards. J. Environ. Hort. 18:1-4.

Lindroth, R.L. and G.O. Batzli. 1984. Plant phenolics as chemical defenses: Effects of natural phenolics on survival and growth of prairie voles (Microtus ochrogaster). J. Chem. Ecol. 10:229-244. 
Lindroth, R.L., G.O. Batzli, and S.I. Avildsen. 1986. Lespedeza phenolics and Penstemon alkaloids effects on digestion efficiencies and growth of voles. J. Chem. Ecol. 12:713-728.

Marquis, R.J. and G.O. Batzli. 1989. Influence of chemical factors on palatability of forage to voles. J. Mammal. 70:503511.

Merwin, I.A., J.A. Ray, and P.D. Curtis. 1999. Orchard groundcover management systems affect meadow vole populations and damage to apple trees. HortScience 34:271-274.

Meyer, M. and W.H. Karasov. 1991. Chemical aspects of herbivory in arid and semiarid habitats, p. 167-188. In: R.T. Palo and C.T. Robbins (eds.). Plant defenses against herbivory. CRC Press, Boca Raton, FL.
Muenscher, W.C. 1951. Poisonous plants of the Untied States. Macmillan, New York.

Reichardt, P.B., J.P. Bryant, B.R. Mattes, T.P. Clausen, F.S. Chapin, III and M. Meyer. 1990. Winter chemical defense of Alaskan balsam poplar against snowshoe hares. J. Chem. Ecol. 16:1941-1959.

Richmond, M. and C.H. Conaway. 1969. Management breeding and reproductive performance of the vole, Microtus ochrogaster, in a laboratory colony. Lab. Anim. Care 19:80-87.

Ries, S., R. Baughan, M.G. Nair, and R. Schutzki. 2001. Repelling animals from crops using plant extracts. HortTechnology 11:302-307.

Roy, J. and J.M. Bergeron. 1990. Role of phenolics of coniferous trees as deterrents against debarking behavior of meadow voles (Microtus pennsylvanicus). J. Chem. Ecol. 6:801-808.

Swain, T. 1978. Plant-animal coevolution: A synoptic view of the Paleozoic and Mesozoic, p. 3-19. In: J.B. Harborne (ed.). Biochemical aspects of plant and animal coevolution. Academic Press, London.

Tahvanainen, J., P. Niemela, and H. Henttonen. 1991. Chemical aspects of herbivory in boreal forest: Feeding by small rodents, hares, and cervids, $\mathrm{p}$. 115-132. In: R.T. Palo and C.T. Robbins (eds.). Plant defenses against herbivory. CRC Press, Boca Raton, FL.

Tojo, E. 1991. (+)-Narcidine, a new alkaloid from Narcissus pseudonarcissus. J. Nat. Prod. 54:1387-1388. 